\title{
APPLICATION OF MONOCLONAL ANTIBODIES TO IMMUNOHISTOCHEMISTRY
}

\author{
Kenjiro YaSUda, Masahide ShiOZaWA and Sadakazu Aiso \\ Department of Anatomy, School of Medicine, Keio University, Shinjuku, Tokyo 160
}

Since Köhler and Milstein (9) developed a method to prepare the monoclonal antibody $(\mathrm{McAb})$, the antibody has widely used in every field of biological science. As is well known, the McAb recognizes only one determinant of the antigen with high specificity and contains antibody class or subclass in the uniform pattern. Moreover, the hybridoma, once established, produces the homogeneous antibody molecule in the culture media continuously. On the other hand, McAb does not precipitate the antigen in the form of the immune complex of the large molecule, and shows cross-reactivity (11).

In the application of McAb to immunohistochemical studies, it is necessary to pay particular attention to the condition in its utilization on tissue sections, in addition to taking the characteristics of the McAb mentioned above in consideration.

I. Interpretation of the reaction sites

$\mathrm{McAb}$ reacts with only one of the determinants on the antigen molecule. The positive reaction site represents the site of a determinant, but does not always show the localization and the configuration of whole antigen molecule. On the assume that an antigen is furnished with three determinants on the molecule and each of them is designated as A, B and C, respectively (Fig. 1). Supposing these determinants are distributed within a cell in such a pattern as shown in Fig. 2, the localization of determinant $\mathrm{A}$ is shown as Fig. 3-A, determinant $\mathrm{B}$ as Fig. 3-B and determinant $\mathrm{C}$ as Fig. 3-C. The immunoreaction site with the polyclonal antibody (PcAb) prepared to the same antigen is shown as Fig. 3-A $+\mathrm{B}+\mathrm{C}$, when the $\mathrm{PcAb}$ reacts with three determinants equally and does not contain any other rective factors. Under hypothetical conditions, the reactive sites with McAb, shown in Fig. 3 -A, B or C, do not coincide with that of PcAb. But in practice, it might be very rare that each determinant of an antigen distributes itself as scatteringly within a cell as to show wide variation of the localization as is shown in Fig. 3. In other words, the distribution pattern of a determinant shown immunohistochemically by use of $\mathrm{McAb}$ almost represents the sites and configuration of the antigen molecule, with some exceptions.

II. Specificity and intensity of the reaction.

The intensity of the immunoreaction on the tissue is usually weaker with McAb than with PcAb, probably because the number of the reacted determinants are less with the former than with the latter. This is the main reason why the PAP method (16), ABC technique (7) or other methods $(8,17)$ are effective to intensification of the immunoreaction and to decrease background staining. The figures of the positively reactive sites demonstrated by means of $\mathrm{McAb}$ are usually far clearer than those by

This study was supported in part by grants from the Ministry of Education, Science and Culture, Japanese Government, Nos. 61480093 and 63770029 . 

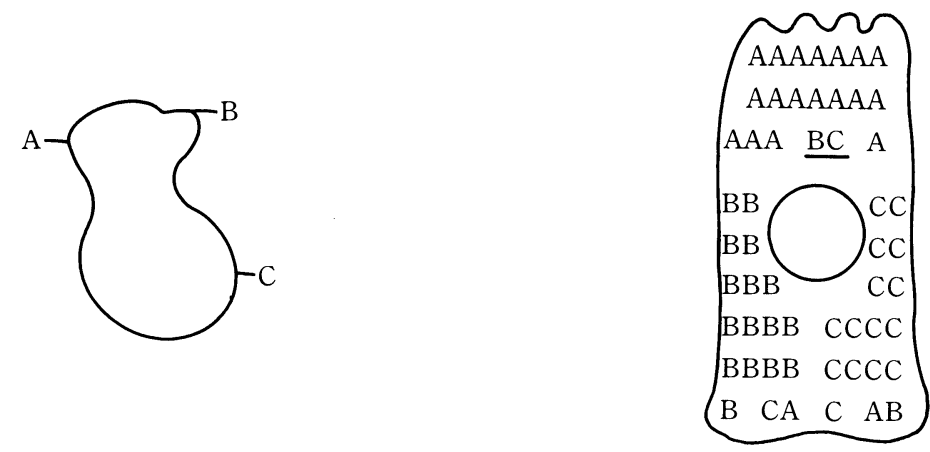

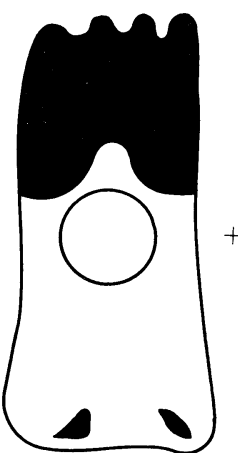

A

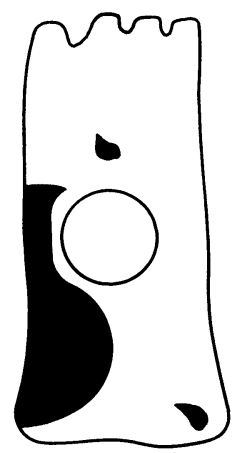

B

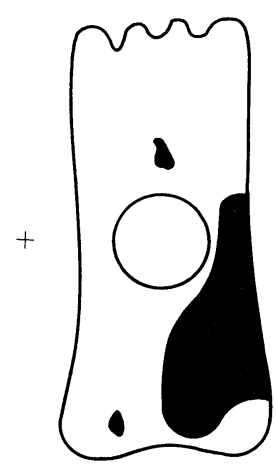

$\mathrm{C}$

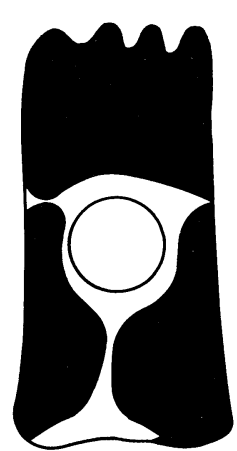

$\mathrm{A}+\mathrm{B}+\mathrm{C}$

Fig. 1. Determinants on an antigen molecule.

FIG. 2. Localization of determinants in a cell.

FIG. 3. Localization of reaction products showing the sites of determinants $A, B$ and $C$, respectively with monoclonal antibodies, and $\mathrm{A}+\mathrm{B}+\mathrm{C}$ in all with polyclonal antibody.

use of PcAb. This is probably because the specificity of McAb is so high and each antibody molecule has such even binding activity to the target determinant that $\mathrm{McAb}$ may more selectively and concentratedly lodge on the sites of the determinants of the antigen molecule than in the immunoreaction with PcAb.

In some cases in the immunohistochemical study, the reaction appears stronger with McAb than with PcAb. As shown in Fig. 4, under the condition that $\mathrm{A}$ is the dominant determinant among those of the antigen, the reaction with anti-A McAb is stronger than that with $\mathrm{PcAb}$ which reacts with small number of the determinats $\mathrm{A}, \mathrm{B}$ and C. This kind of reaction pattern may occur when a definite determinant is concentrated in a definite area within a cell.

\section{Cross-reactivity}

The presence of cross-reactivity in the use of McAb has been pointed out in several reports $(3,4,12)$ and summarized by Lane and Kaprowki (11). As previously described, $\mathrm{McAb}$ recognizes single determinant of the antigen but not the antigen molecule. Thus the immunoreactive sites imply distribution of the definite determi- 


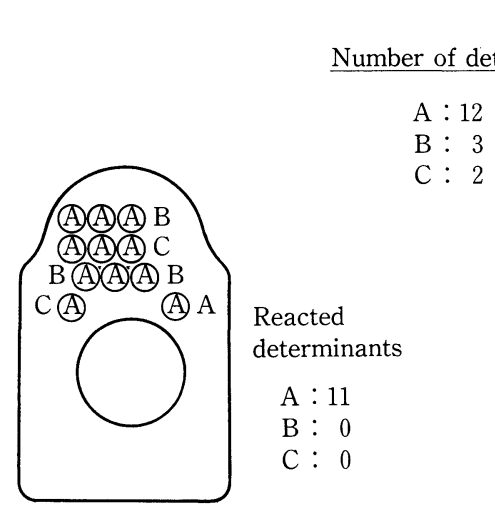

The determinants reacted exclusively to monoclonal anti-A antibody

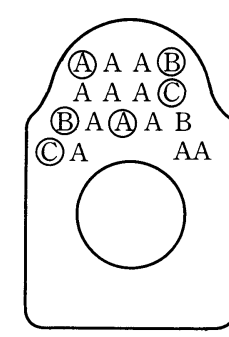

The determinants reacted to the mixture of anti-A, -B and -C, each of which has similar titer and molecules

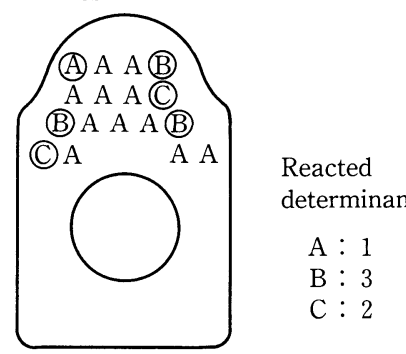

The determinants reacted to the antibody mixture, in which anti-A has low titer or is less in volume

FIG. 4. Explanation for the stronger reactivity with monoclonal antibody than with polyclonal antibody in immunohistochemistry.

nant in the tissue. If the determinant, which is the same as, common with or genetically similar to the determinant to which McAb was prepared, are present in the different kind of tissues, organs and species, the immunoreaction is also positive. This fact is often misunderstood to be that the immunoreaction with McAb abounds in non-specificity. Taking the results of an immunohistochemical study on the distribution of gamma-glutamyl transpeptidase (Gamma-GTP) in rats by use of $\mathrm{McAb}$ prepared against rat kidney Gamma-GTP, positive reactions were obtained not only in the kidney but also in liver pancreas, epididymis and so on (19). The reaction sites in rat kidney represent the site of the determinant of $51 \mathrm{Kd}$ polypeptide, but those in the other tissue represent the site of the determinants which are the same as or similar to $51 \mathrm{Kd}$ polypeptide or genetically similar to it (Table 1). Since it is unknown whether the determinant in those tissues is $51 \mathrm{Kd}$ polypeptide or genetically similar to $51 \mathrm{Kd}$ polypeptide, the immunohistochemical results in tissue other than the kidney are explained to be obtained utilizing the cross-reactive nature of McAb. It must be emphasized that the cross-reactivity is strictly distinguished from the nonspecific reaction in the immunohistochemistry.

Supposing a McAb was obtained, it is very difficult to know the sphere of the specimens in which the cross-reactivity could be found. The cross-reaction between Thy-1 and intermediate filaments (3), between Vk-TEPG 15 and Thy-1 (12) and bet- 
TABLE 1. Polypeptides recognized by monoclonal antibodies

\begin{tabular}{ccc}
\hline $\begin{array}{c}\text { Anti-rat kidney } \\
\gamma \text {-GTP } \\
\text { (Yasuda et al.) }\end{array}$ & $\begin{array}{c}\text { Anti-rabbit kidney } \\
\text {-GTP } \\
\text { (Komatsu et al.) }\end{array}$ & $\begin{array}{c}\text { Anti-human kidney } \\
\gamma \text {-GTP } \\
\text { (Shiozawa et al.) }\end{array}$ \\
\hline $51 \mathrm{Kd}$ & $54.6 \mathrm{Kd}$ & $69 \mathrm{Kd}$ \\
\hline
\end{tabular}

ween each isoenzyme of carbonic anhydrase (4) are reported, but these are found rather unexpectedly or by chance than by investigating wide range of specimens containing various kind of antigens systematically. The immunohistochemistry is in the same situation. There is apparently a limitation in searching for the tissues or organs which are expected to contain the antigens possibly cross-reactive to the McAb. At least it is desirable to observe the immunoreaction with a McAb on the same organ or tissue, from which the antigen was prepared, in different animals or on different organs of the same species of animal, as shown in Table 2.

IV. Miscellaneous remarks in the utilization of McAb in immunohistochemistry

When the immunoreaction cannot be recognized even after making a careful survey on the immunological specifictiy of the $\mathrm{McAb}$, the selection of the fixative, concentration of the antibody solution, duration of the reaction with the antibody and the selection of the procedure in the preparation of tissue sections, one of the possibilities to be considered is that the target determinant could be hidden by some unknown materials or entangled in the three-demensional conformation of the antigen molecule. To make the target determinant in the tissue easily reactive to the antibody, several treatments are introduced, and some of them are useful, depending on the nature of the antigen to be examined; treatment with trypsin $(2,6)$, with pronase (5) with pepsin (13), with urea (1) and with warm PBS (19).

The immunological characteristics must be strictly examined before applying McAb to the immunohistochemical study. Taking Gamma-GTP as an example, the kind of polypeptide which McAb recognizes (Table 1), class or subclass of McAb (Table 3) and ratio of the inhibition of the activity of the antigen by McAb when $\mathrm{McAb}$ is prepared against the enzyme (Table 4) must be confirmed. In this respect, the use of McAb prepared in own laboratory is recommended. These characteristics cannot be examined in detail when the McAb from a commercial source is used,

TABEL 2. Cross-reactivity of monoclonal antibodies

\begin{tabular}{|c|c|c|c|c|c|c|c|c|c|}
\hline & \multicolumn{3}{|c|}{ Rat } & \multicolumn{3}{|c|}{ Rabbit } & \multicolumn{3}{|c|}{ Human } \\
\hline & Kidney & Pancreas & $\begin{array}{l}\text { Epidi- } \\
\text { dymis }\end{array}$ & Kidney & Pancreas & $\begin{array}{l}\text { Epidi- } \\
\text { dymis }\end{array}$ & Kidney & Pancreas & $\begin{array}{l}\text { Epidi- } \\
\text { dymis }\end{array}$ \\
\hline $\begin{array}{l}\text { anti-rat } \\
\gamma \text {-GTP }\end{array}$ & + & + & + & - & - & - & + & - & - \\
\hline $\begin{array}{l}\text { anti-rabbit } \\
\gamma \text {-GTP }\end{array}$ & - & - & - & + & + & + & - & - & - \\
\hline $\begin{array}{l}\text { anti-human } \\
\gamma \text {-GTP }\end{array}$ & - & + & - & - & - & - & + & + & + \\
\hline
\end{tabular}


TABLE 3. Antibody typing

\begin{tabular}{ccc}
\hline $\begin{array}{c}\text { Anti-rat kidney } \\
\gamma \text {-GTP } \\
(19)\end{array}$ & $\begin{array}{c}\text { Anti-rabbit kidney } \\
\text {-GTP } \\
(10)\end{array}$ & $\begin{array}{c}\text { Anti-human kidney } \\
\gamma \text {-GTP } \\
(15)\end{array}$ \\
\hline $\operatorname{IgG}_{1} \kappa$ & $\operatorname{IgG}_{2 \mathrm{a}} \lambda$ & $\mathrm{IgG}_{1} \kappa$ \\
\hline
\end{tabular}

TABLE 4. Inhibition of enzyme activity by monoclonal antibodies

\begin{tabular}{ccc}
$\begin{array}{c}\text { Anti-rat kidney } \\
\gamma \text {-GTP } \\
(19)\end{array}$ & $\begin{array}{c}\text { Anti-rabbit kidney } \\
\gamma \text {-GTP } \\
(10)\end{array}$ & $\begin{array}{c}\text { Anti-human kidney } \\
\gamma \text {-GTP } \\
(15)\end{array}$ \\
\hline $15 \%$ & $46.7 \%$ & $86 \%$ \\
\hline
\end{tabular}

because the antigen from which McAb is prepared cannot be obtained.

$\mathrm{McAb}$ does not make precipitated immune complex with the antigen. Therefore, the antibody is not absorbed by the antigen by only mixing two in test tube. This fact makes the control experiment more difficult to be performed than in the case of using PcAb. Thus, the culture medium, supernatant of the myeloma cells, omitting the second or third layer in the staining procedure and the irrelevant $\mathrm{McAb}$ are used in the control experiment.

The immunohistochemical study with $\mathrm{McAb}$ is designed to demonstrate the distribution of a determinant of the antigen but not the antigen molecule itself. Still the positive sites demonstrated show the site and configuration of the antigen in the tissue section. In practice, it is required to take the nature of McAb and the characteristic condition in the application to the tissue section into consideration.

\section{LITERATURE}

1. Brandtzaeg, P.: Tissure preparation methods for immunocytochemistry. In: Techniques in Immunocytochemistry, vol. 1, ed. by G. R. Bullock and P. Petrusz, Academic Press, London, 1-75, 1982.

2. Curren, R. C. and Gregory, J.: Demonstration of immunoglobulin in cryostat and paraffin sections of human tonsil by immunofluorescence and immunoperoxidase techniques. Effects of processing on immunohistochemical performance of tissues and on the use of proteolytic enzymes to unmask antigens in sections. J. Clin. Path. 31; 974-983, 1978.

3. Dulbecco, R., Unger, M., Bologna, M., Battiforra, H., Syka, P. and Okada, S.: Crossreactivity between Thy-1 and a component of intermediate filaments demonstrated using a monoclonal antibody. Nature 292; 772-774, 1981.

4. Erickson, R. P., Kay, G., Hewett-Emmett, D., Tashian, R. E. and Claflin, J. L.: Crossreasctions among carbonic anhydrases I, II and III studied by binding tests and with monoclonal antibodies. Biochem. Genet. 20; 809-819, 1982.

5. Finley, J. .C. W., Grossman, G. H., Dimeo and Petrusz, P.: Somatostatin-containing neurons in the rat brain: widespread distribution revealed by immunocytochemistry after pretreatment with pronase. Am.J. Anat. 153; 483-488; 1978. 
6. Hautzer, N. W., Wittkuhn, J. F. and McCaughey, W. T. E.: Trypsin digestion in immunoperoxidase stainig. J. Histochem. Cytochem. 28; 52-53, 1980.

7. Hsu, S. M., Raine, L. and Fanger, H.: Use of avidin-biotin-peroxidase complex (ABC) in immunoperoxidase techniques: $\mathrm{A}$ comparison between $\mathrm{ABC}$ and unlabled antibody (PAP) procedures. J. Histochem. Cytochem. 29; 577-580, 1981.

8. Kamiya, H. and Imamura, M.: Sensitive immunohistochemical demonstration of human lymphoctye cell-surface antigens in tissue sections by using a combined PAP-avidin-biotin and repeated PAP method. Clin. Immunol. 14, Suppl. 5, 191-200, 1982 (in Japanese).

9. Köhler, G. and Milstein, C.: Continuous cultures of fused cells secreting antibody of predefined specificity. Nature. 256; 494-497, 1975.

10. Komatsu, T., Yamashita, S. and Yasuda, K.: Preparation of monoclonal antibody to rabbit kidney gamma-glutamyl transpeptidase and its cross-reactivity analysis in immunohistochemistry. Acta histochem. cytochem. 20;163-176, 1987.

11. Lane, D. and Kaprowski, H.: Molecular recongnition and the future of monoclonal antibodies. Nature 296; 200-202, 1982.

12. Pillemer, E. and Weissman, I. L.: A monoclonal antibody that detects a Vk-TEPG 15 idiotypic determinant cross-reative with a Thy-1 determinant. J. Exp. Med. 153; 1068-1079, 1981.

13. Reading, M.: A digestion technique for the reduction of background staining in the immunoperoxidase method. J. Clin. Path. 30; 88-90, 1977.

14. Shiozawa, M., Aiso, S. and Yasuda, K.: Immunohistochemical study on human organs. Use of monoclonal antibodies to human $\gamma$-glutamyl transpeptidase. Abstract for the 92th Annual Meeting of Japanese Association of Anatomists, p. 150, 1982 (in Japanese).

15. Shiozawa, M., Aiso, S. and Yasuda, K.: Immunohistochemical study with monoclonal antihuman $\gamma$-glutamyl transpeptidase antibody on salivary gland. Abstract for the 93th Annual Meeting of Japanese Association of Anatomists, p. 70, 1983 (in Japanese).

16. Sternberger, L. A.: Immunocytochemistry, 2nd Edition, Chapter 5, John Wiley \& Sons, New York, Chichester, Brisbane, Toronto, 1979.

17. Yamashita, S., Taniguchi, S., Hoshiai, O., Tawara, H. and Yasuda, K.: Immunoperoxidase techniques with a combined use of PAP and ABC procedures: Application to immunohistochemical studies using monoclonal antibodies. Okajimas Folia Anat. Jpn. 61; 378398, 1984 .

18. Yasuda, K.: Immunohistochemistry with monoclonal antibodies: A comparison to that with polyclonal antibodies. Acta histochem. cytochem. 17; 689-690, 1984.

19. Yasuda, K., Yamashita, S., Aiso, S., Shiozawa, M. and Komatsu, T.: Immunohistochemical study of $\gamma$-glutamyl transpeptidase with monoclonal antibodies. I. Preparation and characteristics of monoclonal antibodies to $\gamma$-glutamyl transpeptidase. Acta histochem. cytochem. 19; 589-600, 1986. 